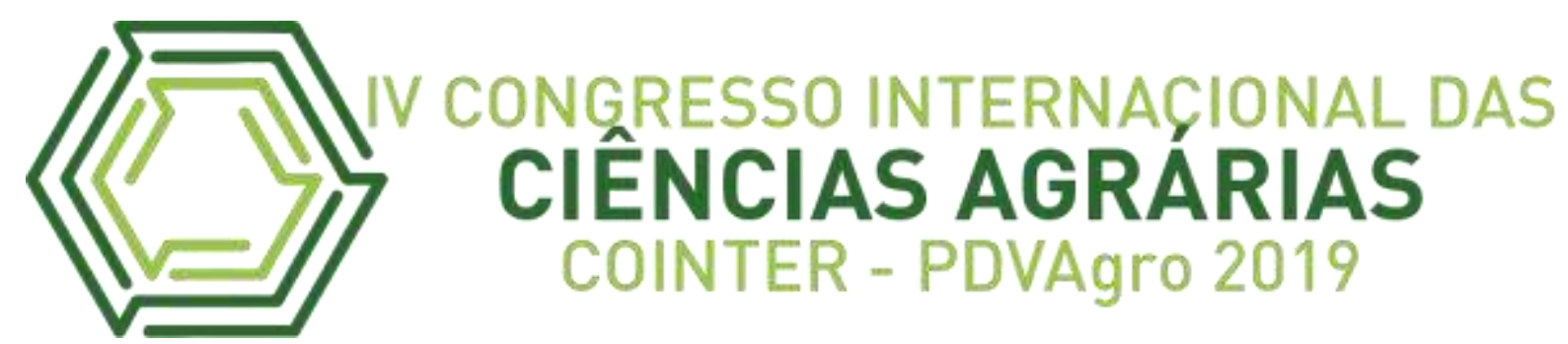

\title{
EFICIÊNCIA DO HÚMUS DE MINHOCA NO DESEMPENHO DO MILHO CRIOULO NO NORDESTE PARAENSE
}

\section{EFFICIENCY EARTHWORM HUMUS IN THE PERFORMANCE OF MAIZE LANDRACE CULTIVARS IN NORTHEAST OF PARÁ}

\author{
Apresentação: Comunicação Oral \\ Nelson Ken Narusawa Nakakoji ${ }^{1}$; Ítala Duam Souza Narusawa ${ }^{2}$; Cleison Freitas da Silva ${ }^{3}$; \\ Cícero Paulo Ferreira ${ }^{4}$; Gilberta Carneiro Souto ${ }^{5}$
}

DOI: https://doi.org/10.31692/2526-7701.IVCOINTERPDVAgro.2019.0183

\begin{abstract}
Resumo
A vermicompostagem é um tipo de compostagem que utiliza minhocas além dos microorganismos naturais para degradar a matéria orgânica. As minhocas se alimentam da matéria orgânica e a transformam em húmus, um adubo nobre com quantidades expressivas de todos os nutrientes prontamente assimiláveis para as plantas. Existem relatos dos efeitos positivos do húmus de minhoca, sobre os mais diversos cultivos realizados pelos agricultores. Quando o húmus é produzido com as condições minimamente controladas, aproveita-se muitos resíduos e rejeitos orgânicos existentes nas propriedades, como estercos e restos vegetais, que podem, em muitos casos, suprir a necessidade de adubo em uma horta de pequeno ou médio porte, especialmente nas condições das agriculturas de base ecológica. Nesse sentido, este trabalho teve como objetivo avaliar a eficiência do húmus de minhoca na adubação do milho crioulo (Zea mays L.). O delineamento experimental utilizado foi o inteiramente casualizado (DIC), os tratamentos utilizados foram T0 (Tratamento testemunha), T1 (2 kg de húmus/m²), T2 (4 kg de húmus $\left./ \mathrm{m}^{2}\right)$, T3 (6 kg de húmus $\left./ \mathrm{m}^{2}\right)$ e T4 $\left(8 \mathrm{~kg}\right.$ de húmus $\left./ \mathrm{m}^{2}\right)$. Cada tratamento teve 5 repetições, totalizando 25 parcelas. Como resultado se constatou que o tratamento T3 apresentou maior incremento em todos os parâmetros avaliados da cultura. O húmus de minhoca por proporcionar incremento na produção do milho crioulo é uma opção aplicável e pode ser uma alternativa de adubação; a dosagem de melhor desempenho agronômico para o milho local foi de $6,59 \mathrm{~kg} / \mathrm{m}^{2}$. A cultura do milho apresentou melhor desempenho de aproveitamento do húmus de minhoca do que olerícolas como o jambu (Acmella oleracea[(L.) R. K. Jansen].
\end{abstract}

Palavras-Chave: Vermicompostagem, Adubação Orgânica, Zea mays L., Matéria orgânica, Variedade local.

\footnotetext{
${ }^{1}$ Graduando em Agronomia, IFPA - Campus Castanhal, narusawanelsonken@ gmail.com

${ }^{2}$ Graduanda em Agronomia, IFPA - Campus Castanhal, dudanarusawa@gmail.com

${ }^{3}$ Graduando em Agronomia, IFPA - Campus Castanhal, cleisonfreitasbr@ gmail.com

${ }^{4}$ Doutor em Ciências Agrárias pela Universidade Federal Rural da Amazônia, Docente do IFPA - Campus Castanhal, cicero.ferreira@ifpa.edu.br

${ }^{5}$ Doutora em Agronomia/Fitotecnia pela UFERSA, Coordenadora do curso de agronomia e docente no IFPA Campus Castanhal, gilberta.souto@ifpa.edu.br
} 


\begin{abstract}
The vermicoposting is a type of composting that uses earthworms in addition to the natural microorganisms to degrade organic matter. Earthworms feed on organic matter and transform it into humus, is a noble fertilizer with expressive amounts of all readily assimilable nutrients to the plants. There are reports of the positive effects of earthworm humus on the most diverse crops cultivated by farmers. When humus is produced under minimally controlled conditions, it takes advantage of many residues and organic wastes on the properties, such as manure and vegetable debris, which can in many cases meet the need for fertilizer in a small or medium-sized garden, especially under the conditions of ecologically based farms. In doing, so this study aimed to evaluate the efficiency earthworm humus in the fertilization of maize landrace cultivars (Zea mays L.). The experimental used was completely randomized designer (CRD), the used treatments had been: T0 (control treatment), T1 (2 kg of humus/m²), T2 (4 kg of humus $\left./ \mathrm{m}^{2}\right), \mathrm{T} 3\left(6 \mathrm{~kg}\right.$ of humus $\left./ \mathrm{m}^{2}\right)$ e $\mathrm{T} 4\left(8 \mathrm{~kg}\right.$ of humus $\left./ \mathrm{m}^{2}\right)$. Each treatment had 5 replications, totaling 25 plots. As a result, T3 treatment showed higher increment in all evaluated parameters of the culture. The earthworm humus by providing an increment in the production of maize landrace is an applicable option and maybe an alternative fertilizer; the dosage of better agronomic performance for maize landrace cultivar was $6,59 \mathrm{~kg} / \mathrm{m}^{2}$ ). The maize landrace cultivation showed a better performance of earthworm humus than oleraceous such as jambu (Acmella oleracea[(L.) R. K. Jansen].
\end{abstract}

Keywords: Vermicomposting, Organic fertilizer, Zea mays L, Organic matter, Landrace.

\title{
Introdução
}

Pertencente à família Poaceae, espécie Zea mays L., o milho é uma cultura de grande importância econômica, sendo uma das mais cultivadas e estudadas em todo mundo. Atualmente, é uma das espécies de maior interesse agronômico e fornece vários produtos com aplicações em diversos setores (GLAT, 2010). Segundo dados do IBGE (2006), a cultura do milho por sua versatilidade, tanto no seu uso na produção animal quanto no aspecto social, se consolidou uma das mais importantes do Brasil no setor agrícola.

As populações crioulas de milho, também chamadas de variedades locais, tradicionais ou landraces, são variedades cultivadas por comunidades indígenas e agricultores familiares, e que geralmente são submetidas à uma sucessiva seleção para características relacionadas à produção de cada safra, onde as melhores espigas são selecionadas, proporcionando bom desempenho nas condições ambientais especificas em que são cultivadas (TEIXEIRA et al., 2005).

Fernandes et al. (1999) e Paiva et al. (2012) demonstraram experimentalmente, que o milho é um grande extrator de nitrogênio. Nessa perspectiva, como os solos do nordeste paraense apresentam baixas propriedades químicas (GAMA et al., 2007), e isso interfere 
diretamente na fertilidade do solo, bem como experiências com adubação orgânica em folhosas, culturas de ciclo curto, na área experimental de olericultura do campus Castanhal tem apresentado limitação quanto a absorção de nitrogênio (CAVALCANTE, 2015), o uso de plantas de ciclo anual como o milho, podem ter respostas diferenciadas no aproveitamento do húmus de minhoca, rico em nitrogênio.

Erig et al. (2002), ao trabalharem em condições de cultivo no Paraná, mostraram que o húmus de minhoca é uma alternativa de adubação viável, tendo resultados positivos na produção de grãos de milho, porém necessitando de mais estudos.

Nesse sentido, este trabalho teve como objetivo avaliar a eficiência do húmus de minhoca na adubação do milho crioulo no nordeste paraense.

\section{Fundamentação Teórica}

A vermicompostagem se apresenta como uma opção para adubação de milho crioulo, pois é um tipo de compostagem que utiliza minhocas além dos micro-organismos naturais para degradar a matéria orgânica. O processo ocorre mais rápido que a compostagem na ausência de minhocas e produz como substrato o húmus de minhoca. Este é um adubo rico em nutrientes e ótimo para as plantas (EMBRAPA, 2018).

De uma maneira geral, é possível fazer húmus de qualquer material que se decomponha aasim qualquer resíduo orgânico disponível e não aproveitado em alguma propriedade rural pode ser utilizado. A vermicompostagem, que nada mais é do que as excreções da minhoca, quando se aplica ao solo, tem atuação benéfica sobre suas características físicas, químicas e biológicas, favorecendo a sua conservação e auxiliando o desenvolvimento das plantas (SCHIEDECK, 2008).

Com isso, o aproveitamento de forma integral e racional de todos os recursos disponíveis dentro da propriedade rural, com a introdução de novos componentes tecnológicos, como a vermicompostagem, permite o aumento da estabilidade dos sistemas de produção, maximizando a eficiência deles, reduzindo os custos e melhorando significativamente a produtividade (KONZEN \& ALVARENGA, 2007).

A matéria orgânica incorporada ao solo pelo húmus funciona como fonte de energia para microrganismos úteis, melhora a estrutura e o arejamento do solo evitando a compactação, aumenta a capacidade de armazenar umidade, regula a temperatura do solo, diminui a fixação do fósforo, aumenta a CTC e protege contra lixiviação (MALAVOLTA et al. 2002). Existem 
relatos dos efeitos positivos do húmus de minhoca, sobre os mais diversos cultivos realizados pelos agricultores. Quando o húmus é produzido com as condições minimamente controladas, aproveita-se muitos resíduos e rejeitos orgânicos existentes nas propriedades, como estercos e restos vegetais, que podem, em muitos casos, suprir a necessidade de adubo em uma horta de pequeno ou médio porte, especialmente nas condições das agriculturas de base ecológica. No entanto esse é um importante recurso natural que é pouco aproveitado pelos agricultores em suas propriedades (SCHIEDECK, 2008).

\section{Metodologia}

O experimento foi desenvolvido no setor de olericultura do IFPA - Campus Castanhal, no município de Castanhal, Pará (S117'53.51" W4755'1.83"), localizado na mesorregião metropolitana de Belém, no período de agosto de 2018 a fevereiro de 2019. O clima da cidade de Castanhal segundo a classificação de Köppen e Geiger é Af (tropical equatorial) com uma pluviosidade média anual de $2432 \mathrm{~mm}$ (CLIMATE, 2018). (Imagem 01)

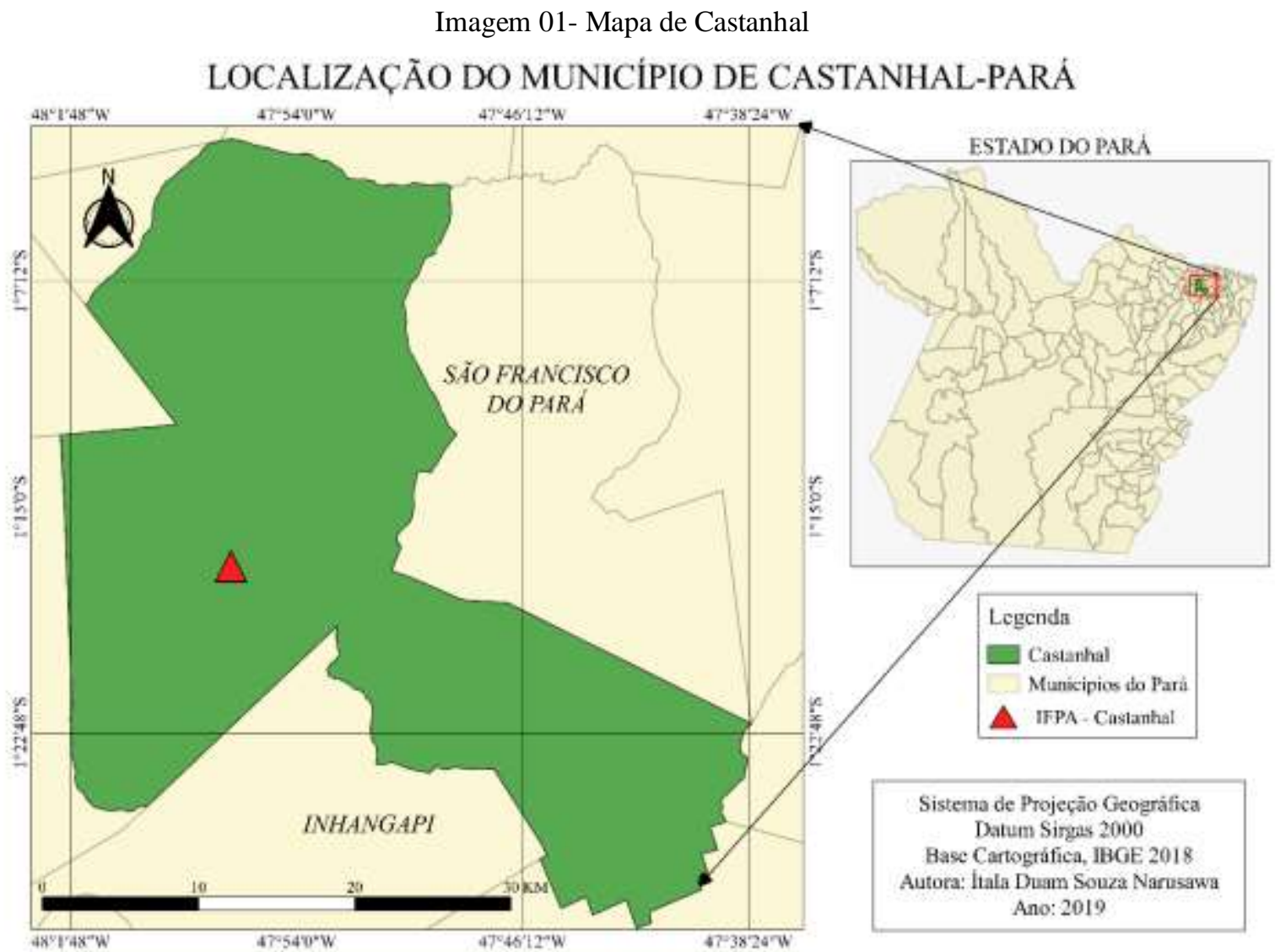

Fonte: Autores, 2019. 
O milho crioulo utilizado no experimento, foi doado por um agricultor familiar do sítio Dedê (1 $\left.1^{\circ} 20^{\prime} 02 \mathrm{~S}, 4^{\circ} 00^{\prime} 13.2^{\prime \prime} \mathrm{W}\right)$, situado na cidade de Santa Luzia do Pará. Em relato, o proprietário informou que seu cultivo se iniciou na propriedade a partir da década de 70, e desde então, sempre realiza a reserva das sementes para futuros plantios através da seleção das maiores espigas de milho.

Anteriormente, a área experimental havia recebido um experimento com tratamento de biofertilizante a base de esterco bovino, de fermentação anaeróbica e posteriormente deixado em pousio por seis meses. O lugar apresentava uma vegetação com gramíneas espontâneas e densa, onde foi efetuado uma limpeza e levantamento de leiras representando as parcelas.

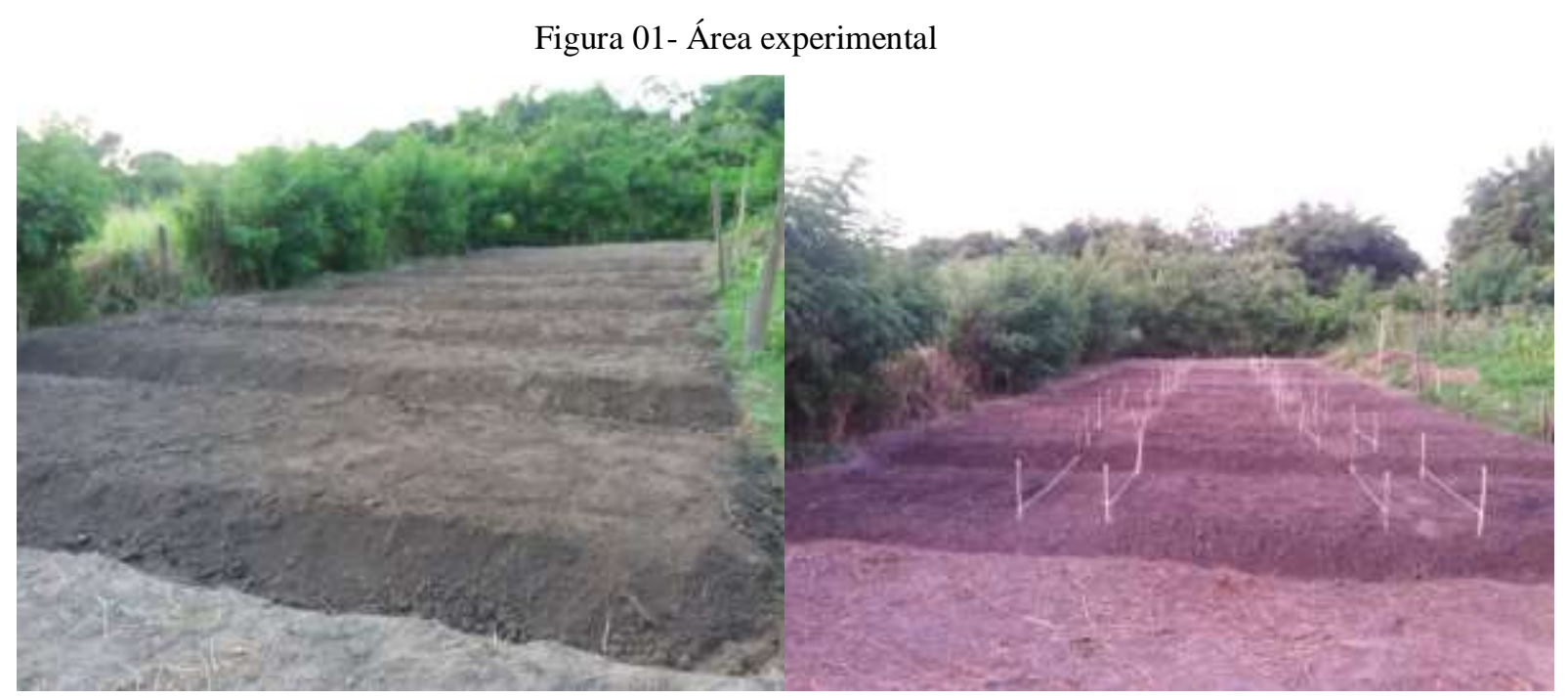

Fonte: Autores, 2019

Após a limpeza do local, foram realizadas a coleta de solo da área do experimento, e no minhocário do IFPA - Campus Castanhal, coletou-se o húmus. Em seguida, encaminhados para o laboratório de solos Terra, localizado em Goiânia-GO, onde foram realizadas as análises de fertilidade do solo e do húmus, seguindo a metodologia de análise da Embrapa (2009).

O delineamento experimental utilizado foi o inteiramente casualizado (DIC), e os tratamentos utilizados foram T0 (Tratamento testemunha), T1 (2 kg de húmus/m²), T2 (4 kg de húmus $\left./ \mathrm{m}^{2}\right)$, T3 (6 kg de húmus $\left./ \mathrm{m}^{2}\right)$ e T4 $\left(8 \mathrm{~kg}\right.$ de húmus $\left./ \mathrm{m}^{2}\right)$. Cada tratamento teve 5 repetições, totalizando 25 parcelas experimentais de $1,5 \mathrm{~m}$ por $2 \mathrm{~m}$. O plantio do milho foi distribuído no espaçamento de $0,75 \mathrm{~m}$ entre linhas e $0,20 \mathrm{~m}$ entre plantas, totalizando três linhas de cultivo em cada parcela, com 5 plantas por metro linear, sendo considerados para análise somente as 6 
plantas do interior da parcela, para evitar o efeito bordadura. Cada parcela apresentava $0,8 \mathrm{~m}$ de distância entre si como isolamento entre os tratamentos. (Figura 01)

Figura 01- Croqui da Plantação de milho na horta no IFPA- Castanhal

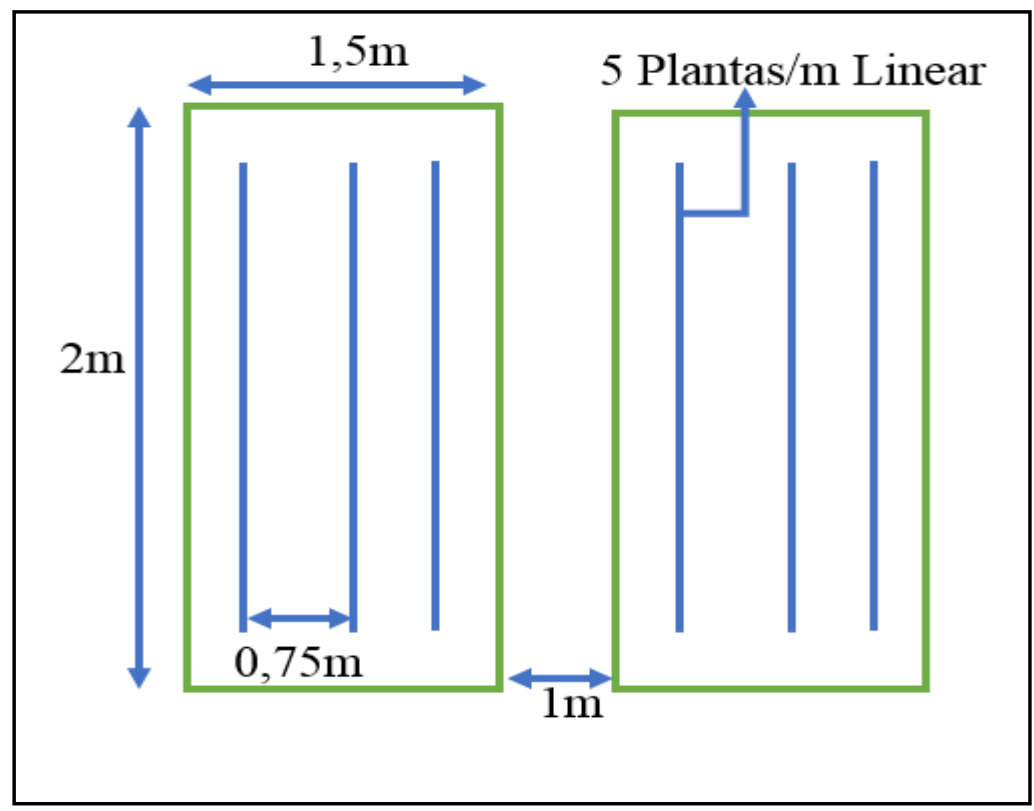

Fonte: Autores, 2019

Para Fancelli (2010), as etapas V4 e V12 do milho são os estágios mais demandantes de nutrientes. Por essa razão, a primeira aplicação dos tratamentos ocorreu na semeadura, depois aos 15 dias e pôr fim aos 30 dias, divididas em 3 doses iguais. (Figura 02)

Figura 02- Ciclo vegetativo do milho

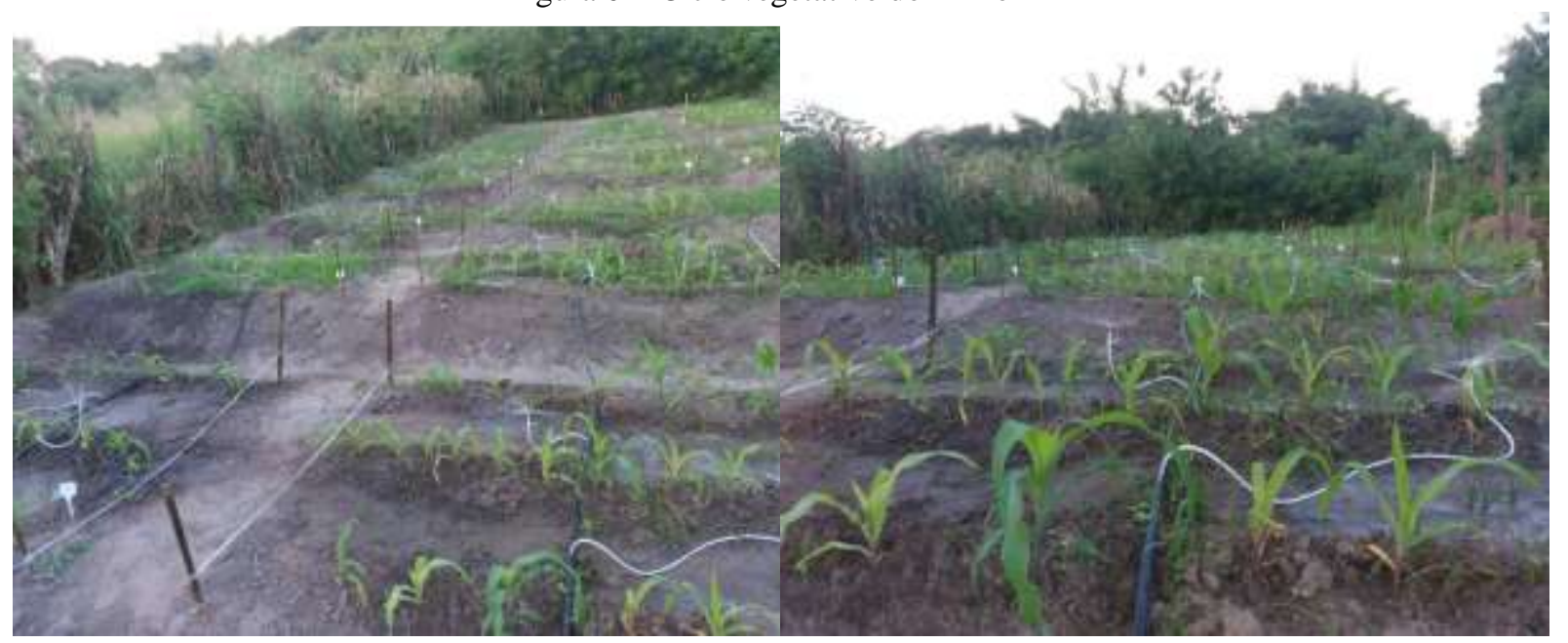

Fonte: Autores, 2019 
No final do ciclo vegetativo, ocorreu a aferição dos seguintes componentes: massa fresca, massa seca, diâmetro do colmo e altura da planta. Os dados obtidos foram submetidos à análise de variância (Teste F), regressão de equação polinomial e teste de Tukey, todos a 5\% de significância. Os programas computacionais utilizados foram o Sisvar e o Microsoft Excel. (Figura 03, 04)

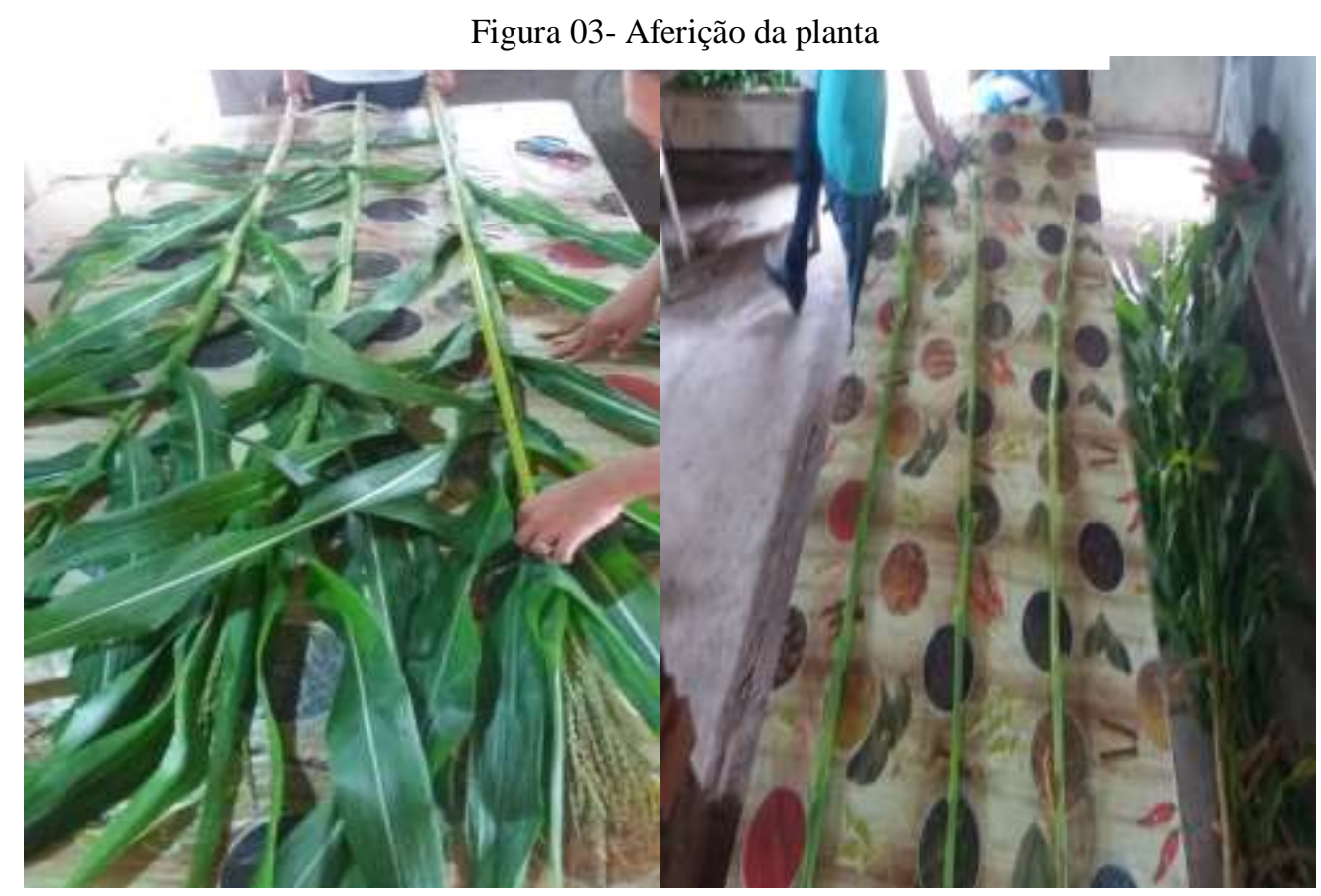

Fonte: Autores, 2019

Figura 04- Aferição da planta/massa fresca e massa seca

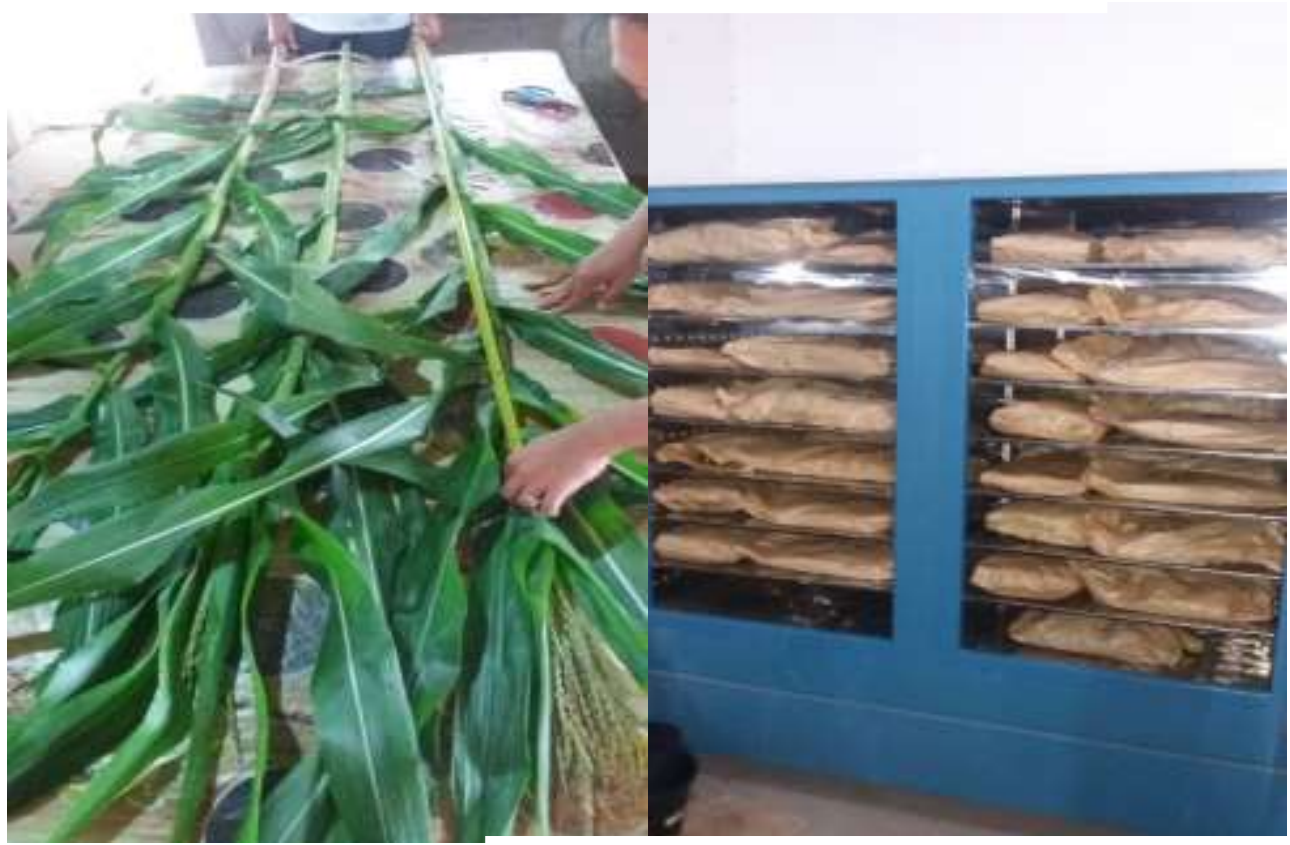

Fonte: Autores, 2019 


\section{Resultados e Discussão}

A partir dos teores obtidos pela análise granulométrica do solo, e pela utilização do triângulo textural (Silte 14 \%, Argila 17\% e Areia 69\%), pode-se classificar o solo como Franco Arenoso.

$\mathrm{Na}$ análise química do solo (Tabela 01), pode se notar ausência de alumínio e teores de 3 cmolc/dm³ de $\mathrm{Ca}+\mathrm{Mg}$. Segundo Brasil \& Cravo (2007), esses teores de Cálcio e Magnésio são considerados medianos, e pela ausência de alumínio solúvel, não há necessidade de correção de acidez do solo.

Tabela 01 - Análise de solo utilizado no experimento

\begin{tabular}{|c|c|c|c|c|c|c|c|c|c|}
\hline \multirow[b]{2}{*}{ Profundidade } & \multirow{2}{*}{$\begin{array}{c}\mathrm{pH} \\
\mathrm{em} \\
\mathrm{CaCl}_{2}\end{array}$} & MO & $\mathrm{N}$ & $\mathrm{K}$ & $\mathrm{P}$ & $\mathrm{Ca}$ & $\mathrm{Mg}$ & $\mathrm{Al}$ & CTC \\
\hline & & $\mathrm{g} \mathrm{kg}^{-1}$ & $\%$ & $\ldots . .$. & -3 & $\ldots$ & & led & \\
\hline $0-20 \mathrm{~cm}$ & 5,3 & 12,0 & 0,06 & 52,0 & 56,0 & 2,6 & 0,4 & 0,0 & 5,23 \\
\hline
\end{tabular}

Fonte: Laboratório Terra (2018)

$\mathrm{Na}$ análise do húmus de minhoca (Tabela 02), percebe-se uma relação baixa de carbono/nitrogênio e teores consideráveis de macronutrientes, principalmente do nitrogênio e cálcio. O húmus de minhoca possui 21,6 vezes mais nitrogênio do que o teor encontrado no solo analisado e transformando para a mesma grandeza dimensional da análise de solos (cmolc

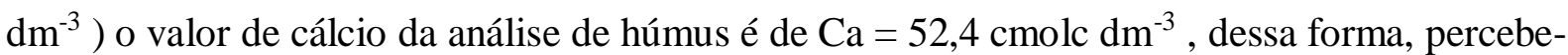
se que o vermicomposto possui 21,15 vezes mais Cálcio do que o teor encontrado no solo, com isso corroborando os resultados de incremento demonstrado posteriormente. Segundo He et al. (2012), o nitrogênio é o elemento que mais influencia o número, comprimento, diâmetro e produtividade de espigas comerciais e grãos do milho.

Tabela 02 - Análise do Húmus de minhoca utilizado no experimento

\begin{tabular}{|c|c|c|c|c|c|c|c|}
\hline & $\mathrm{pH}$ & $\mathrm{N}$ & $\mathrm{P}$ & $\mathrm{K}$ & $\mathrm{Ca}$ & $\mathrm{Mg}$ & $\mathrm{C} / \mathrm{N}$ \\
\hline Umidade & $\begin{array}{c}\mathrm{em} \\
\mathrm{CaCl}_{2}\end{array}$ & & & & & & - \\
\hline $19,9 \%$ & 6,8 & 1,3 & 0,29 & 0,44 & 1,05 & 0,38 & $10 / 8$ \\
\hline
\end{tabular}


Sendo assim, ao analisar as doses de húmus de minhoca no cultivo do milho local, constatou-se que houve efeito positivo das doses de húmus nos índices de crescimento analisados (altura, diâmetro do colmo, massa verde e massa seca) com valor de significância a $(\mathrm{P}<0,05)$ (Tabela 03), refletindo boas características do húmus de minhoca como fertilizante. $\mathrm{O}$ aumento na matéria seca (MS) em função do aumento da dosagem de adubação orgânica, também foi observado por Barbosa et al. (2007).

Tabela 03 - Tratamento testemunha (T0), tratamento com $2 \mathrm{~kg}$ de húmus de minhoca/m² (T1), tratamento com $4 \mathrm{~kg}$ de húmus de minhoca $/ \mathrm{m}^{2}$ (T2), tratamento com $6 \mathrm{~kg}$ de húmus de minhoca $/ \mathrm{m}^{2}(\mathrm{~T} 3)$, tratamento com $8 \mathrm{~kg}$ de húmus de minhoca $/ \mathrm{m}^{2}$ (T4).

\begin{tabular}{llccc} 
Tratamento & Altura $(\mathrm{m})$ & $\begin{array}{c}\text { Diâmetro do } \\
\text { colmo }(\mathrm{mm})\end{array}$ & $\begin{array}{c}\text { Massa Verde } \\
(\mathrm{kg})\end{array}$ & $\begin{array}{c}\text { Massa Seca }(\mathrm{kg}) \\
\text { T0 }\end{array}$ \\
\hline T1 & $1,37 \mathrm{a}$ & $13,84 \mathrm{a}$ & $0,90 \mathrm{a}$ & $0,15 \mathrm{a}$ \\
T2 & $2,50 \mathrm{ab}$ & $15,61 \mathrm{ab}$ & $1,31 \mathrm{ab}$ & $0,16 \mathrm{a}$ \\
T3 & $2,18 \mathrm{~d}$ & $18,28 \mathrm{~b}$ & $1,58 \mathrm{abc}$ & $0,22 \mathrm{ab}$ \\
T4 & $22,15 \mathrm{c}$ & $1,97 \mathrm{bc}$ & $0,27 \mathrm{~b}$ \\
CV $(\%)$ & $1,82 \mathrm{bc}$ & $18,64 \mathrm{bc}$ & $2,06 \mathrm{c}$ & $0,21 \mathrm{ab}$ \\
& 8,28 & 9,47 & 21,32 & 18,78
\end{tabular}

Médias, na coluna, seguidas de letras diferentes, diferem entre si $(\mathrm{P}<0,05)$ pelo teste Tukey. Fonte: Elaborado pelos autores (2019)

A análise da estatística demonstrou que no tratamento T3, as plantas exibiram maior altura, com média de 2,18 m, proporcionando melhor incidência solar e mais realização de fotossíntese; o diâmetro do colmo, foi o de maior diâmetro $(22,15 \mathrm{~mm})$, ocasionando maior fluxo de xilema e floema (MAGALHÃES et al., 1995), e por fim o incremento da massa acumulada pela planta, ou seja, da massa seca novamente T3 foi significativo estatisticamente, com 0,27 gramas. Pode-se observar, que a incrementação proporcionada pelo húmus de minhoca reforça o trabalho de Erig et al. (2002), que constata que o húmus de minhoca pode ser utilizado como fonte alternativa de adubação na cultura do milho.

Entretanto, o tratamento T4 tendo a maior quantidade de adubação ( $8 \mathrm{~kg}$ de húmus $\left./ \mathrm{m}^{2}\right)$, proporcionou menor incremento em relação ao tratamento T3 (6 kg de húmus $\left./ \mathrm{m}^{2}\right)$, em especial na análise da massa seca. Taiz \& Zeiger (1998), afirmam que as plantas comumente respondem ao aumento na dose de insumos com incrementos crescentes, até o ponto em que outro fator limitante ao crescimento passe a predominar, reduzindo o incremento. Na matéria seca das plantas (com exceção do carbono, hidrogênio e oxigênio), o Nitrogênio é três vezes mais 
abundante que qualquer outro elemento e o incremento da matéria seca está associado a quantidade de $\mathrm{N}$, disponibilizado para a planta (MALAVOLTA, 1981; MALAVOLTA et al.,1997).

Todavia, para Wetselaar \& Farquhar (1980), existe uma possível ocorrência de perdas de nitrogênio da parte aérea, continuamente durante todos os estádios de crescimento da planta, resultando em perdas de tecidos das raízes e da parte aérea, de perdas de compostos nitrogenados solúveis por lavagem pela chuva, orvalho ou água de irrigação, e por volatilização. De acordo com Duarte et al. (2003), no milho essas perdas de massa se tornam presentes quando há maior nível de Nitrogênio do que a taxa de absorção pelas raízes.

Segundo Beleze et al. (2003), existe correlação positiva entre a massa seca (MS) e o aumento da produção do grão. Assim, ajustou-se uma função polinomial para o comportamento da massa seca em função da dose de adubação do húmus de minhoca (Gráfico 01). O valor de F significativo foi de 0,017 , sendo o coeficiente de determinação de $98 \%$, o erro amostral da massa seca oscilando entre $-0,008 \mathrm{~kg} / \mathrm{m}^{2}$ a $0,0104 \mathrm{~kg} / \mathrm{m}^{2}$, sendo este um modelo preditor de grande assertividade. Deste modo, pôde obter através da função modelada $\mathbf{y}=\mathbf{- 0 , 0 0 1 2} \mathbf{x}^{\mathbf{3}}+$

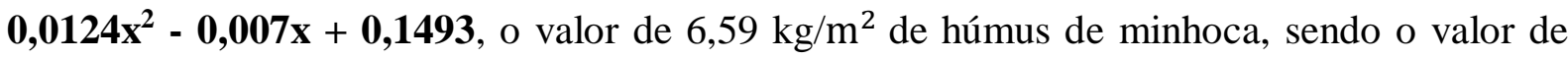
máxima adubação para o incremento da matéria seca, ratificando o teste de médias, sendo o tratamento T3 (6 kg de húmus $/ \mathrm{m}^{2}$ ) o mais bem colocado entre os tratamentos.

Gráfico 01 - Linha resposta da massa seca em função da dosagem de húmus de minhoca por $\mathrm{m}^{2}$ a Significância do teste $\mathrm{F}<0.05$.

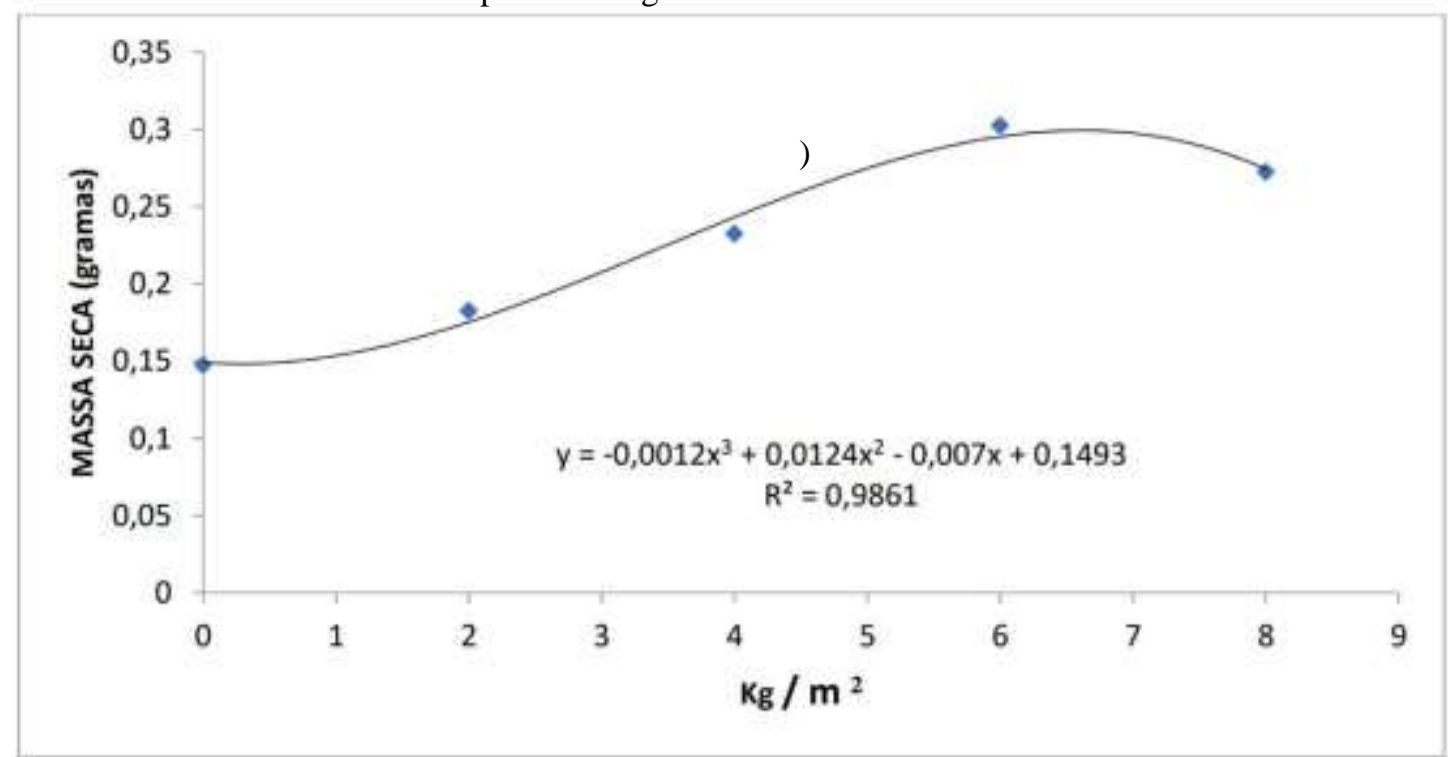

Fonte: Elaborada pelos autores (2019) 
Fazendo comparativo com o jambu (Acmella oleracea[(L.)R. K. Jansen], o milho crioulo conseguiu expressar sua máxima potencialidade com menos quantidade de adubação de húmus de minhoca, pois para essa olerícola bastante apreciada no estado do Pará, sua dose de melhor expressão agronômica foi de $10 \mathrm{~kg}$ de húmus de minhoca $/ \mathrm{m}^{2}$, descrita por Souto (2016) no mesmo setor de olericultura (IFPA-Canpus Castanhal). (Figura 05)

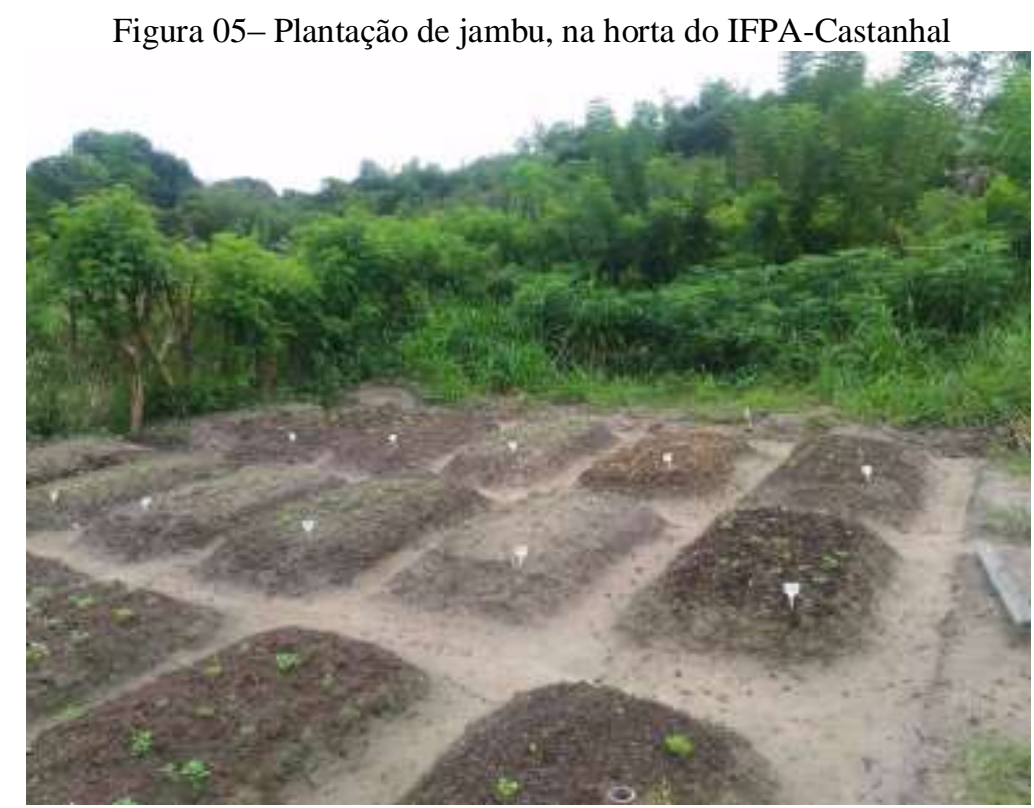

Fonte: Autores, 2019.

O nitrogênio oriundo da matéria orgânica é assimilado pelas plantas de 2 a $5 \%$ no período de um ano (MOREIRA \& SIQUEIRA, 2006). O milho, por ser uma cultura de ciclo mais longo que as hortaliças, a adubação de húmus de minhoca é mais bem aproveitada. Também em alcance de sistema radicular, o milho consegue colonizar com maior profundidade que as folhosas, possuindo dupla vantagem agronômica, proporcionando rendimento de adubação. 


\section{Conclusões}

Como resultado se constatou que o tratamento T3 apresentou maior incremento em todos os parâmetros avaliados da cultura. O húmus de minhoca por proporcionar incremento na produção do milho crioulo é uma opção aplicável e pode ser uma alternativa de adubação; a dosagem de melhor desempenho agronômico para o milho local foi de $6,59 \mathrm{~kg} / \mathrm{m}^{2}$. A cultura do milho apresentou melhor desempenho de aproveitamento do húmus de minhoca do que olerícolas como o jambu (Acmella oleracea[(L.) R. K. Jansen].

\section{Referências}

BARBOSA, G. M. C.; TAVARES, F, J.; BRITO, O. R.; FONSECA, I. C. Efeito residual do lodo de esgoto na produtividade do milho safrinha. Revista Brasileira de Ciência do Solo, v.31, p.601-605, 2007.

BELEZE et al. Avaliação de Cinco Híbridos de Milho (Zea mays, L.) em Diferentes Estádios de Maturação. 1. Produtividade, Características Morfológicas e Correlações. R. Bras. Zootec., v.32, n.3, p.529-537, 2003.

BRASIL \& CRAVO. Recomendações de Adubação e Calagem para o Estado do Pará. 1. Ed. Belém/PA, 2007. 46 p.

CAVALCANTE, A. E. C. Extensão tecnológica no uso de resíduos orgânicos: Sua transformação em adubo para sustentabilidade da agropecuária no município de Irituia-PA, dissertação de mestrado, IFPA/ Campus Castanhal, 2015.

CLIMATE. Clima: Castanhal, 2018. Disponível em: https://pt.climatedata.org/location/26632/. Acesso em 06 de julho de 2018.

DUARTE et al. Acúmulo de matéria seca e nutrientes em cultivares de milho originárias de clima tropical e introduzidas de clima temperado. Revista Brasileira de Milho e Sorgo, v.2, n.3, p.1-20, 2003.

ERIG, P. R.; VERONA, M. M.; SEIDEL, G. O.; MORO, E.; FEY, E.; CASTRO, A. M. C. Produtividade da cultura do milho em resposta a adubação com húmus de minhoca, XI Encontro Anual de Iniciação Científica, 2002. Maringá - PR. UEM, 1p.

EMPRESA BRASILEIRA DE PESQUISA AGROPECUÁRIA - EMBRAPA. Manual de análises químicas de solos, plantas e fertilizantes. 2. ed. Brasília, 2009. 627 p. 
EMBRAPA, Vermicompostagem. Disponível em: https://www.embrapa.br/busca-depublicacoes/-/publicacao/698959/manual-de-vermicompostagem/. Acesso em 20 março de 2018.

FANCELLI, A. L. Boas práticas para uso eficiente de fertilizantes na cultura do milho. Informações agronômicas, n. 131, p. 1-16, 2010.

FERNANDES, L A. et al. Preparo do dolo e adubação nitrogenada na produção de grãos e matéria seca e acúmulo de nutrientes pelo milho. Pesquisa agropecuária Brasileira, Brasília, v.34, n 9, p. 1691-1698, 1999.

GAMA et al. Recomendações de Adubação e Calagem para o Estado do Pará. 1. Ed. Belém/PA, 2007. 25 p.

GLAT, D. Presente e futuro da cultura de milho no mundo. Informativo Pioneer, Santa Cruz do Sul, RS, ano XV, n. 31, 2010. Disponível em: https://www.agrolink.com.br/noticias/aevolucao-da-produtividade-do-milho-no-brasil_130498.html. Acesso em: 05 agosto de 2018.

HE, J.; DUKES, M.D.; HOCHMUTH, G.J.; JONES, J.W.; GRAHAM, W.D. Identificação das melhores práticas de manejo de irrigação e nitrogênio para a produção de milho doce em solos arenosos, utilizando o modelo Ceres- milho. Gainesville, v.109, p.61- 70, 2012.

IBGE. Censo agropecuário. Rio de Janeiro, 2006. 777 p. Disponível em: http://biblioteca.ibge.gov.br/visualizacao/periodicos/51/agro_2006.pdf. Acesso em: 08 agosto de 2018.

KONZEN, E. A. \& ALVARENGA, R. C. Cultivo do Milho: Fertilidade de solos, Adubação Orgânica. Embrapa Milho e Sorgo, $3^{\text {a }}$ edição, 2007.

MAGALHÃES, P. C.; DURÃES, F.O.M.; PAIVA, E. Fisiologia da planta de milho. Circular Técnica n. 20, Embrapa-CNPMS, Sete Lagoas, 1995. 27 p.

MAlaVoltA, E. Manual de Química Agrícola Adubos e Adubação. São Paulo: Nobel, 1981. p.31.

MALAVOLTA, E.; VITTI, G. C.; OLIVEIRA, S. A. Avaliação do estado nutricional das plantas: Princípios, métodos e técnicas de avaliação do estado nutricional. 2.ed. Piracicaba: Potafos, p. 319, 1997.

MALAVOLTA, E.; GOMES, F. P.; ALCARDE, J. C. Adubos e Adubações. São Paulo: Nobel, 2002. p.29- 110 .

PAIVA M. R. F. C. et al. Doses de nitrogênio e de fósforo recomendadas para a produção econômica de milho verde na chapada do Apodi-RN. Revista Caatinga, Mossoró, v. 25, n 4, p 1-10, 2012.

PIRES, A. M. M.; ANDRADE, C. A, SOUZA, N. A. P.; CARMO, J, B.; COSCIONE, A. R.; 
CARVALHO, C. S. Disponibilidade e mineralização do nitrogênio após aplicações sucessivas de LE no solo, estimadas por meio de incubação anaeróbica. Pesquisa Agropecuária Brasileira, v.50, p.333- 342, 2015.

SCHIEDECK, G. A minhocultura e a produção de húmus no contexto da agricultura familiar. Embrapa Clima Temperado. Brasília, DF. Abril. 2008. Disponível em: https://www.embrapa.br/busca-de-publicacoes/-/publicacao/746014/minhocultura-e-roducaode-humus-para-a-agricultura-familiar/. Acesso em: 07 agosto de 2018.

SOUTO, Gilberta Carneiro. Desempenho agronômico a acúmulo de nutrientes pela planta de jambu. 2016. 47f. Tese (Doutorado em Agronomia: Fitotecnia) - Universidade Federal Rural do Semi-Árido (UFERSA), Mossoró-RN, 2016.

TAIZ, L.; ZEIGER, E. Fisiologia Vegetal, 2. Ed., Artmed, 1998. 792.p

TEIXEIRA, F. F.; SOUZA, B. O.; ANDRADE, R. V.; PADILHA, L. Boas práticas na manutenção de germoplasma de variedades crioulas de milho. Sete Lagoas: Embrapa Milho e Sorgo, 2005. 8 p. (Embrapa Milho e Sorgo. Comunicado Técnico,113). Disponível em: https://ainfo.cnptia.embrapa.br/digital/bitstream/CNPMS/17627/1/Com_113.pdf/. Acesso em: 09 agosto de 2018.

MOREIRA F. M. S. \& SIQUEIRA J. O. Microbiologia e Bioquímica do Solo. 2. ed. Lavras/ MG: Ed. UFLA, 2006. 341p.

WETSELAAR, R.; FARQUHAR, G. D. Nitrogen losses from tops of plants. Advances in Agronomy, New York, v. 33, p. 263 - 302, 1980. 